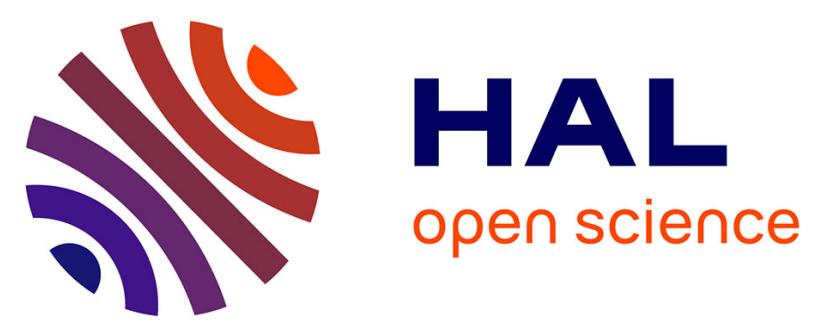

\title{
Developmental delay, intellectual disability, short stature, subglottic stenosis, hearing impairment, onychodysplasia of the index fingers, and distinctive facial features: A newly reported autosomal recessive syndrome
}

André Mégarbané, Sayeeda Hana, Stephany El-hayek, Alicia Gambarini, Mahmoud Taleb Al-ali, Valérie Delague

\section{- To cite this version:}

André Mégarbané, Sayeeda Hana, Stephany El-hayek, Alicia Gambarini, Mahmoud Taleb Al-ali, et al.. Developmental delay, intellectual disability, short stature, subglottic stenosis, hearing impairment, onychodysplasia of the index fingers, and distinctive facial features: A newly reported autosomal recessive syndrome. American Journal of Medical Genetics Part A, 2020, 182 (8), pp.1865-1872. 10.1002/ajmg.a.61730 . hal-03147656

HAL Id: hal-03147656

https://hal-amu.archives-ouvertes.fr/hal-03147656

Submitted on 3 Mar 2021

HAL is a multi-disciplinary open access archive for the deposit and dissemination of scientific research documents, whether they are published or not. The documents may come from teaching and research institutions in France or abroad, or from public or private research centers.
L'archive ouverte pluridisciplinaire HAL, est destinée au dépôt et à la diffusion de documents scientifiques de niveau recherche, publiés ou non, émanant des établissements d'enseignement et de recherche français ou étrangers, des laboratoires publics ou privés. 


\title{
Developmental delay, intellectual disability, short stature, subglottic stenosis, hearing impairment, onychodysplasia of the index fingers, and distinctive facial features: A newly reported autosomal recessive syndrome
}

\author{
André Mégarbané ${ }^{1,2}$ \\ Sayeeda Hana ${ }^{3}$ \\ Alicia Gambarini ${ }^{1}$ \\ Mahmoud Taleb Al-Ali ${ }^{3}$ \\ Stephany El-Hayek ${ }^{3}$
Valérie Delague $^{4}$
}

${ }^{1}$ Institut Jérôme Lejeune, Paris, France

${ }^{2}$ Faculty of Medical Sciences, Lebanese

University, Beirut, Lebanon

${ }^{3}$ Centre for Arab Genomic Studies, Dubai, UAE

${ }^{4}$ Aix Marseille University, Inserm, MMG,

Marseille, France

Correspondence

André Mégarbané, Institut Jerome Lejeune.

37, rue des volontaires 75015 Paris, France.

Email: andre.megarbane@yahoo.fr

\begin{abstract}
We report on a multiply consanguineous Syrian family where two siblings, a boy and a girl, presented with a compilation of symptoms including developmental delay, severe intellectual disability, absent speech, hearing impairment, short stature, subglottic stenosis, increased length of the palpebral fissures, onychodysplasia of index fingers, scoliosis, genu valgum, and malpositioned toes. Two other individuals from the extended family with similar clinical features are also described. Array-CGH did not reveal any pathological copy number variation. Exome sequencing failed to find any causal variants. Differential diagnoses and the possibility that we might be reporting a hitherto unknown syndrome are discussed.

KEYWORDS

consanguinity, dysmorphology, intellectual disability, malformation
\end{abstract}

\section{INTRODUCTION}

It is well established that consanguineous marriages can enhance the probability of rare genetic disorders in offspring. This has been clearly demonstrated in the Arab region, which exhibits some of the highest consanguinity rates worldwide (Ozçelik et al., 2010; Teebi, 2010). The rate of consanguineous unions in the Arab world varies between 20 and 50\%, with first-cousin marriages being the most common (Tadmouri et al., 2009). These high rates of consanguinity have led to the immense burden of autosomal recessive genetic disorders in this region (Teebi \& Teebi, 2005).

In Syria, similar to other countries in the region, marriage between relatives has been a deep-rooted social, cultural and religious practice. The rate of consanguineous unions is $30.3 \%$ in urban Syrian populations and $39.8 \%$ in rural areas (Othman \& Saadat, 2009). Families often have multiple consanguineous marriages over generations resulting in a high burden of genetic disorders (Al-Gazali \& Hamamy, 2014) and the emergence of novel autosomal recessive syndromes (Abou Jamra et al., 2011; Tawamie et al., 2017).

In this article, we describe two siblings from a multiply consanguineous Syrian family, with mainly developmental delay (DD), intellectual disability (ID), absent speech, hearing impairment, short stature, subglottic stenosis, dysmorphic facial features, and onychodysplasia of index fingers. Two other individuals from the extended family, with similar clinical features, are also described. Differential diagnoses and the possibility that we might be reporting a hitherto unknown syndrome are discussed.

\section{MATERIALS AND METHODS}

\section{1 , Subjects}

The subjects were born to healthy second cousin Syrian parents. The siblings underwent extensive work-up including a thorough clinical 
evaluation, skeletal surveys, brain MRIs, echocardiography, and routine blood tests (complete blood count, serum electrolytes, blood glucose levels, cholesterol, thyroid, liver and renal function tests). Two other individuals, from the extended family were investigated remotely. They were not seen in our clinic as they live abroad, but their clinical description and medical history were shared by their parents.

\subsubsection{Molecular analysis}

\section{DNA isolation}

Informed consent for genetic analysis was obtained from the individuals IV.4, V.2, V.3, and V.5 (Figure 1) in compliance with national ethics regulations. Genomic DNA was isolated from blood samples using standard techniques.

\section{Genome-wide microarray CGH analysis}

Genome-wide microarray CGH analysis was done for individual V.3. Genomic DNA was amplified and purified. Following denaturation of probe DNA, hybridization was carried out with the affymetrix cytogenetics whole-genome 2.7 M Array following the manufacturers' standard protocol. Data was collected using GeneChip ${ }^{\circledR}$ Scanner $30007 G$ and CEL files were analyzed using Affymetrix Chromosome Analysis Suite software (ChAS v.1.0.1).

\section{Whole exome sequencing}

Whole exome sequencing (WES) was carried out on four individuals: the two affected individuals (V.3 and V.5), the unaffected father (IV.4) and the unaffected older sister (V.2) (Figure 1). WES was performed by the Genomics and Bioinformatics Platform (GBiM) from the UMR 1251/Marseille Medical Genetics facility, using the NimbleGen SeqCap EZ MedExome kit (total design size $47 \mathrm{Mb}$ ) according to the manufacturer's protocol (Roche Sequencing Solutions, Madison). The SeqCap EZ MedExome kit targets the entire human exome with enhanced coverage of exons from medically relevant genes in Mendelian diseases. Enriched fragment libraries were sequenced on the Illumina NextSeq 500 platform (Illumina, San Diego, CA) using a $150 \mathrm{bp}$ paired-end sequencing protocol. Raw data were mapped to the build of the human genome (hg19) by using BWA 0.7.5 (Li \& Durbin, 2009). Variant calling was subsequently performed using GATK (McKenna et al., 2010) and annotation was done with ANNOVAR (Wang, Li, \& Hakonarson, 2010).

All subsequent steps were performed using VarAFT (Desvignes et al., 2018) (Variant Annotation and Filter tool), an in-house variant filtering and prioritization tool allowing easy and fast selection and segregation of variants from exome or genome data (http://varaft. $\mathrm{eu} /$ ). Considering autosomal recessive inheritance and the presence of consanguinity in the family, we segregated the variants from exome data following a homozygous by descent model. More precisely, we selected homozygous variants shared by the two subjects

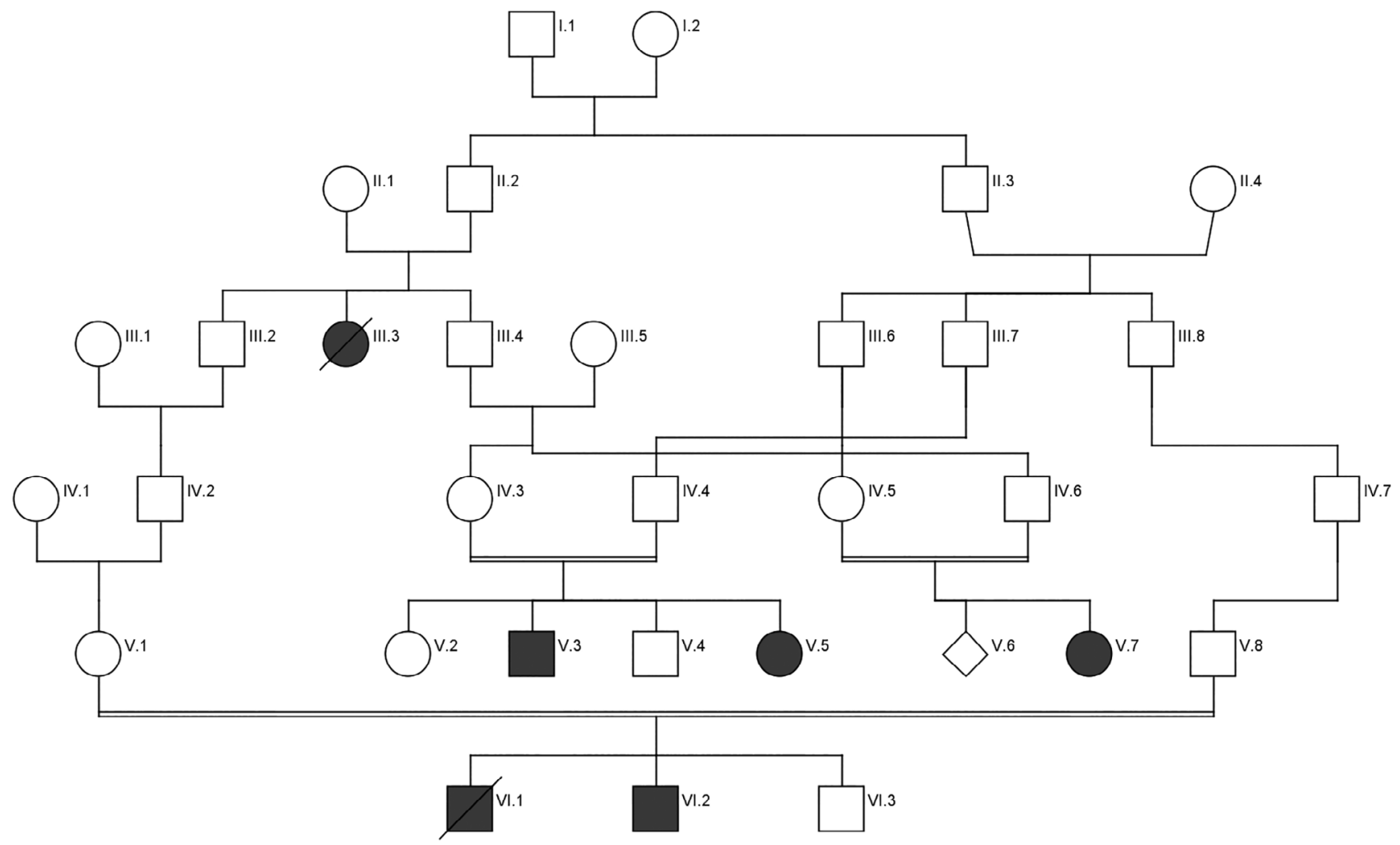

FIGURE 1 Pedigree of the reported family. Black symbols indicate affected individuals. Double lines indicate consanguineous marriages 
(V.3 and V.5), which were also heterozygous in the obligate carrier father (IV.4). For the unaffected older sister V.2, two separate analyses were performed, taking into consideration that she could either be a heterozygous carrier or homozygous for the wild-type allele.

In order to refine the list of candidate nucleotide variations, filtering was performed by removing all variants with allele frequencies $>1 \%$ in the genome aggregation database (gnomAD) database (http:// gnomad.broadinstitute.org/). Additional filtering was also performed using the GME database (Scott et al., 2016), as well as in-house exome databases which include the variants detected by exome sequencing.

In order to predict the deleterious effect of the identified sequence variations, different bioinformatics tools were applied; such as MutationTaster (Schwarz, Rödelsperger, Schuelke, \& Seelow, 2010) (http://www.mutationtaster.org/), SIFT (Kumar, Henikoff, \& Ng, 2009) (http://sift.bii.a-star.edu.sg/) (Kumar et al., 2009), PROVEAN (http:// provean.jcvi.org/index.php/) (Choi, Sims, Murphy, Miller, \& Chan, 2012), PolyPhen-2 (Adzhubei et al., 2010) (http://genetics.bwh. harvard.edu/pph2/), and UMD predictor (http://umd-predictor.eu/) (Salgado et al., 2016).

\section{RESULTS}

\subsection{Clinical report}

For all affected individuals, delivery was normal with no recall of exposure to pre- or perinatal environmental toxins. Family history noted a possible affected aunt who died at age 12 from unknown reasons. She was described as having had a short stature, congenital onychodysplasia of the index fingers (COIF), and ID.

\subsubsection{Subject 1}

This affected boy (V.3 in Figure 1) was seen in our clinics in Beirut, Lebanon at the age of 14 years and 4 months. He is the second child of the family. When he was born, the mother was 20 years old and the father 30 . Birth weight was $3,500 \mathrm{~g}$ (60th centile), but neither the length nor the occipito-frontal circumference (OFC) measures were available. Since birth, one of the major complaints was an abnormal breathing and stridor. Developmental milestones were delayed, as he started walking without help at the age of 4 years but with an
FIGURE 2 Frontal views of individual 1 (a), 2 (b), 3 (c), and 4 (d) at the ages of 15 years, 7 months, 14 years, and 2 years, respectively. Note the thin lips, short philtrum, long palpebral fissures in all four subjects. Distinguishing features include inverted left nipple in individual 1 and upslanting palpebral fissures in individuals 2 and 3 [Color figure can be viewed at wileyonlinelibrary.com] (a)

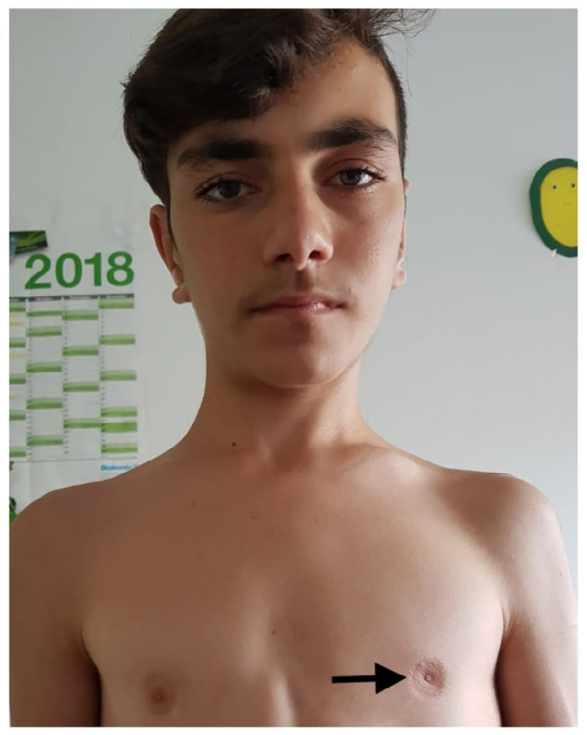

(c)

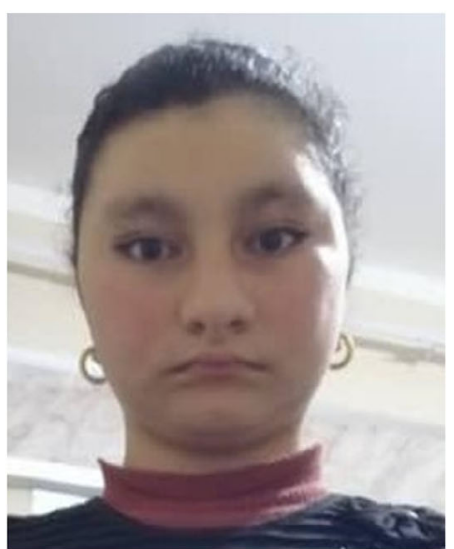

(b)

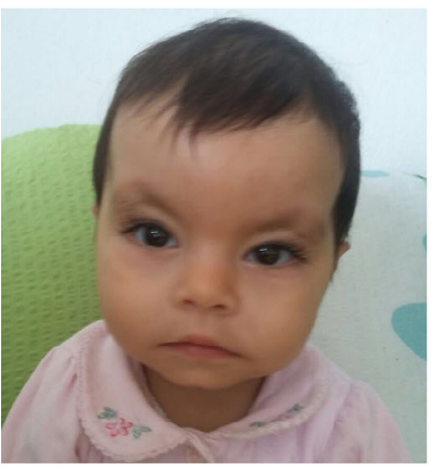

(d)

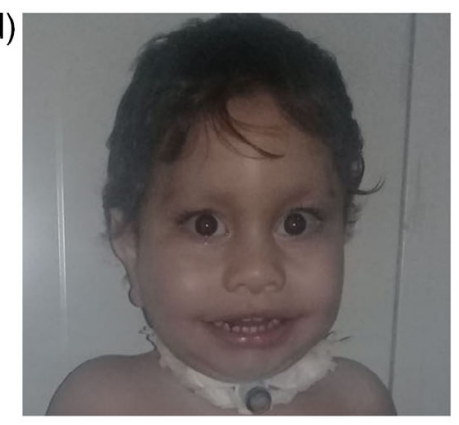


abnormal gait. He started to babble in syllables only at age 5. According to the parents, various investigations were performed in their own community in Syria, and reported as "normal."

When the boy was brought to us for consultation, he was cooperative, could understand simple orders, but could speak only a few words. His height was $139 \mathrm{~cm}(<3 \mathrm{rd}$ centile), weight $31 \mathrm{~kg}$ ( $<3 \mathrm{rd}$ centile), and OFC $52.2 \mathrm{~cm}$ (5th centile). He had a round face, thin lips, a short philtrum, long palpebral fissures with a total length of $3.5 \mathrm{~cm}$ (>97th centile), a normal inner canthal distance of $3 \mathrm{~cm}$ (Figure 2a); onychodysplasia of the index fingers, with anonychia in the left index and hemi-micro-onychia in the right one (Figure 3a); inverted left nipple; a genu valgum; and broad halluces (Figure 4a). Joint laxity, and 2 small café-au-lait spots were noted as well (Table 1). Neurological, heart examinations and echocardiography were unremarkable.

A skeletal survey revealed the presence of left lumbar scoliosis of $18^{\circ}$ (Figure $5 a$ ). No skeletal abnormalities of the distal phalanges were noted.

Two years later, he was operated on for his scoliosis. At that time, his OFC was $53 \mathrm{~cm}$ (10th centile), height was $151 \mathrm{~cm}$ (<3rd centile), and weight $40 \mathrm{Kg}(<3 \mathrm{rd}$ centile). A hearing assessment the time showed a mild hearing impairment. A brain MRI was performed but did not show any remarkable findings. After the operation, the individual experienced severe respiratory difficulties and the medical staff considered that it was because of some inflammation of the trachea on a mild subglottic stenosis. At the most recent examination, at the age of 17 years, the individual weighed $42 \mathrm{~kg}$, and his height was $156 \mathrm{~cm}$, both measures below the third centile.

\subsubsection{Subject 2}

Subject 2 (V.5 in Figure 1), a girl born 14 years after her affected brother was seen at age 2 months. At birth, her weight was 2,600 g (10th centile), length $47 \mathrm{~cm}$ (15th centile), and OFC $35 \mathrm{~cm}$ (50th centile). The parents noticed the onychodystrophy of index fingers directly at birth and thought that she had the same diagnosis as her elder brother (Figure $3 \mathrm{~b}$ ). At the time of first presentation at age
2 months, the baby girl weighed $3,000 \mathrm{~g}(<15$ th centile), her length was $46 \mathrm{~cm}$ (< third centile) and OFC $37.5 \mathrm{~cm}$ (15th centile). She had the same clinical manifestations as her affected brother, in addition to a frontal bossing and a flat nasal bridge (Figure $2 b$ ). The length of the palpebral fissures was $3 \mathrm{~cm}$ (>97th centile), and the inner canthal distance $2.2 \mathrm{~cm}$. External genitalia, neurological and heart examinations, brain MRI, as well as echocardiography and x-ray findings, were unremarkable.

At the age of 1 year, the parents noticed that she was not responding to sounds. Audiometry was performed and showed a severe hearing impairment, for which the girl received a cochlear implant. A few days later she had respiratory distress. Clinical investigation revealed a subglottic stenosis for which she was operated. At age 14 months she was diagnosed with epilepsy. At that time, her weight was $9 \mathrm{~kg}$ (25th centile), her length $72 \mathrm{~cm}$ (3rd percentile). She could stand and walk on her tip-toes with help.

At the most recent examination at the age of 40 months, she weighed $13.7 \mathrm{~kg}$ (25th centile), her height was $85 \mathrm{~cm}$ (<3rd centile) and her OFC $51 \mathrm{~cm}$ (75th centile). She was still unable to speak (Table 1).

Examination of the parents and their non-affected children showed a complete absence of all the features present in the affected siblings.

\subsubsection{Subject 3}

Subject 3, a girl (V.7 in Figure 1), had nearly the same clinical presentation and evolution as her first cousins (individuals V.3 and V.5). Her birth weight was $2,000 \mathrm{~g}$ ( $<3 \mathrm{rd}$ centile). A detailed clinical history since birth was not available but according to her parents, her major problems were her severe ID, and some breathing difficulties. She started to walk at the age of 3 years and said a few, often incomprehensible, words at the age of 4 . At age 14, her height was $147 \mathrm{~cm}(3 \mathrm{rd}$ centile) and her OFC $53 \mathrm{~cm}$ (25th centile). She had the same dysmorphic features seen in her cousins with the addition of upslanting palpebral fissures (Figure 2c). Her toes were malpositioned and she also (a)

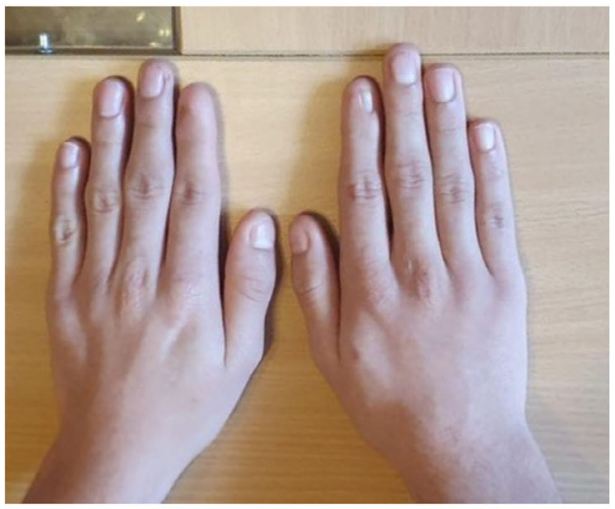

(b)

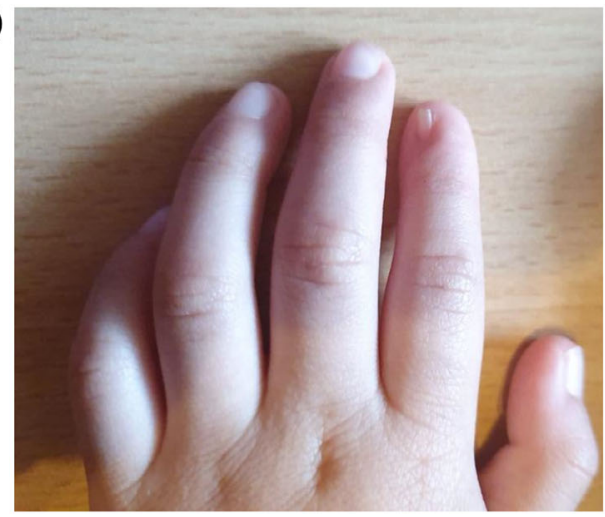

(c)

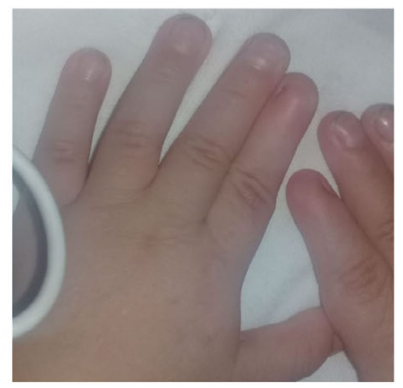

FIGURE 3 Images of subjects' hands. Note the onychodysplasia of the index fingers in (a) individual 1, (b) individual 2, and (c) individual 4 [Color figure can be viewed at wileyonlinelibrary.com] 
(a)

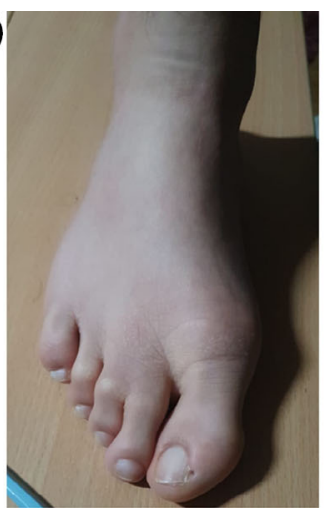

(b)

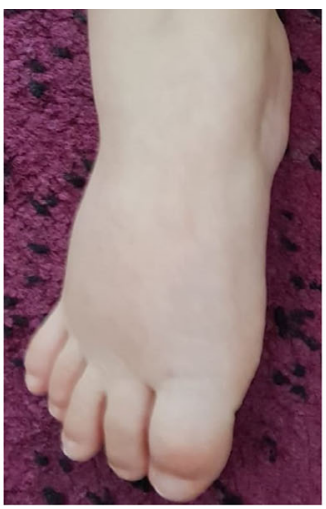

(c)

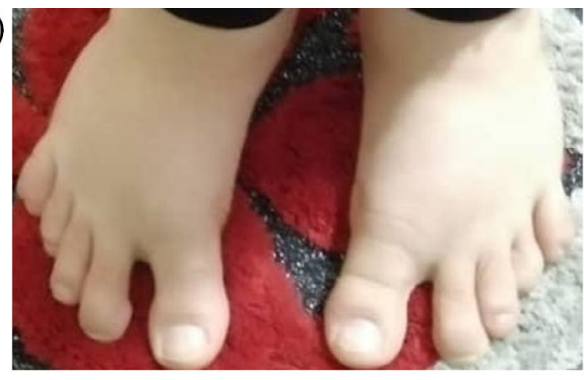

(d)

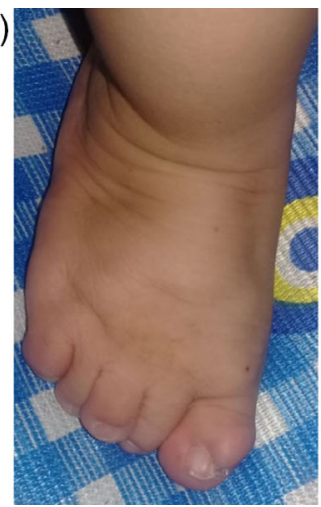

FIGURE 4 Images of feet showing the abnormal halluces and toes. (a) Individual 1, (b) Individual 2, (c) Individual 3, and (d) Individual 4 [Color figure can be viewed at wileyonlinelibrary.com]

TABLE 1 Summary of clinical features in the four reported subjects

\begin{tabular}{|c|c|c|c|c|}
\hline & Subject 1 & Subject 2 & Subject 3 & Subject 4 \\
\hline Gender & Male & Female & Female & Male \\
\hline Weight at birth & $3,500 \mathrm{~g}$ & $2,600 \mathrm{~g}$ & $2,000 \mathrm{~g}$ & $3,200 \mathrm{~g}$ \\
\hline Intellectual disability & Yes & Yes & Yes & Yes \\
\hline Breathing difficulty & Yes & Yes & Yes & Yes \\
\hline Absent/rudimentary speech & Yes & Yes & Yes & Yes \\
\hline Short stature & Yes & Yes & Yes & Yes \\
\hline Scoliosis & Yes & Yes & Yes & No \\
\hline Joint laxity & Yes & Yes & Yes & Yes \\
\hline Round face & Yes & Yes & Yes & Yes \\
\hline Short philtrum & Yes & Yes & Yes & Yes \\
\hline Thin lips & Yes & Yes & Yes & Yes \\
\hline Onychodysplasia of index fingers & Yes & Yes & No & Yes \\
\hline Genu valgum & Yes & No & Yes & Yes \\
\hline Abnormal halluces/toes & Yes & Yes & Yes & Yes \\
\hline Café-au-lait spots & Yes & No & No & No \\
\hline Hearing impairment & Mild & Severe & Mild & $?$ \\
\hline Seizures & No & Yes & No & No \\
\hline
\end{tabular}

had broad halluces, but no onychodysplasia (Figure 3c). Similar to the other subjects, she had scoliosis and genu valgum. In addition, she had knee stiffness and restricted knee movement. Subglottic stenosis was diagnosed at age 9 . Her parents noted that she was not responding to sounds unless they were very loud and suspected that like her cousins might have a hearing impairment (Table 1).

\subsubsection{Subject 4}

Subject 4, a boy (VI.2 in Figure 1), was 26 months of age when his clinical file was reviewed. Since birth, the parents noted respiratory difficulties and hypospadias. At 4-5 months of age, he required a tracheostomy after an unsuccessful attempt to repair a subglottic 
(a)

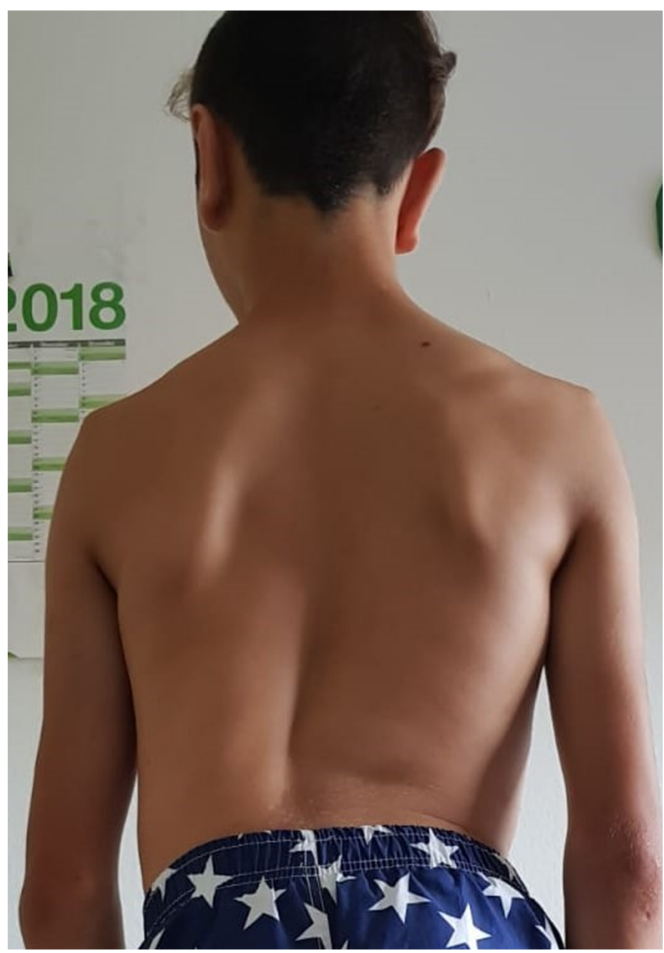

(b)

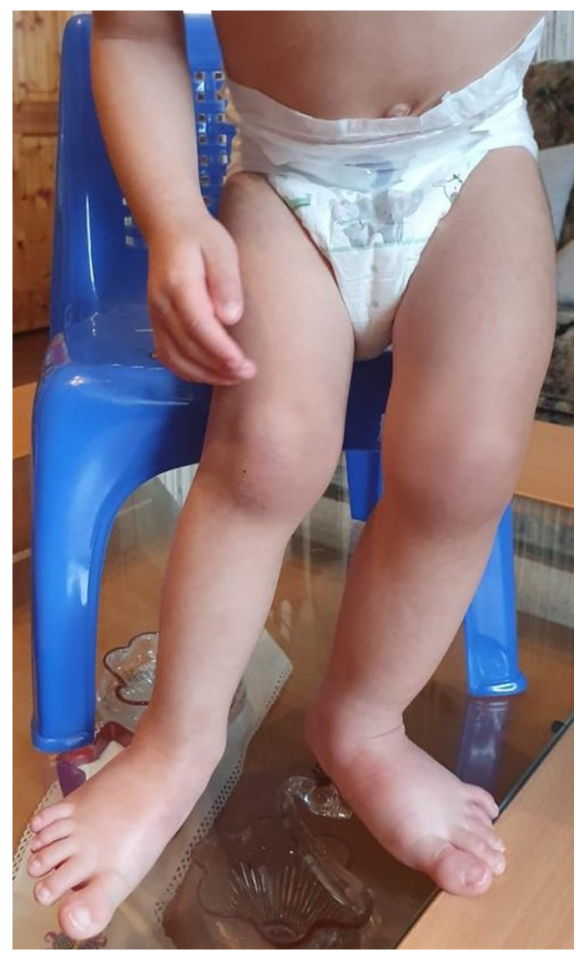

FIGURE 5 Images highlighting individual 1's scoliosis (a) and individual 2's genu valgum (b) [Color figure can be viewed at wileyonlinelibrary.com]

stenosis. He started to walk at the age of 2 years but still needed some help because of abnormal knee motion and severe genu valgum. Clinical description at the age of 26 months, showed that he had the same dysmorphic features as individuals 1 and 2 (Figure 2d), as well as joint laxity and broad abnormal halluces with onychodysplasia, but no scoliosis, possibly due to his young age (Table 1). His OFC was $46 \mathrm{~cm}$ (3rd centile), length $77 \mathrm{~cm}$ (<3rd centile), weight $10.8 \mathrm{~kg}$ (10th centile). According to his parents, his hearing has never been assessed.

It is important to note that individuals 3 and 4 were not clinically examined by us as they live abroad and presently have no access to healthcare facilities. The parents of individuals 3 and 4 , as those of individuals 1 and 2 , have reported a complete absence of the features exhibited by their affected children.

\subsection{Laboratory studies}

Complete blood counts, serum electrolytes, blood glucose levels, triglycerides, cholesterol, amino acid studies of plasma and urine, urinary screening for organic acids, urinalysis, thyroid, liver and renal function tests, were all unremarkable in both siblings (individuals 1 and 2).

\subsection{Molecular studies}

Array-CGH analysis for submicroscopic deletions/duplications performed in the boy revealed no causal CNVs.
We then carried out WES on individuals 1 and 2 (V.3 and V.5), their unaffected father (IV.4) and their unaffected older sister (V.2) (Figure 1). Following the first hypothesis (V.3 and V.5 homozygous, IV.4 heterozygous, and V.2 heterozygous), we obtained 697 variants, of which only 9 had a frequency below $1 \%$ in the gnomAD and GME data set. Of these 9, 6 were frequent (>10\%) in our local database and the other three were either false homozygous or sequencing errors. Moreover, none of the nine variants were in the coding region.

Following the second hypothesis (V.3 and V.5 homozygous, IV.4 heterozygous and $V .2$ homozygous for the normal allele), we obtained 51 variants, of which 4 had a frequency below $1 \%$ in the gnomAD and GME datasets. After applying the local database filter, no variant remained.

\section{DISCUSSION}

The clinical features of the individuals reported here consist of DD, ID, absent/rudimentary speech, hearing impairment, short stature, subglottic stenosis, dysmorphic facial features such as a round face, long palpebral fissures, thin lips and a short philtrum, onychodysplasia of index fingers, and malposition (Table 1). No other ectodermal abnormalities were noted. All subjects exhibited genu valgum except for individual 2. This distinct clinical presentation of the four subjects does not conform to any well-delineated syndrome, raising the possibility of it being a previously unseen disorder. 
To confirm our findings a thorough search was conducted in the face2gene database (http://suite.face2gene.com/lmd/), the POSSUM databases (http://www.possum.net.au), the Online Mendelian Inheritance in Man (https://www.omim.org/), and PubMed (https:// pubmed.ncbi.nlm.nih.gov/). All differential diagnoses were considered with syndromes presenting at least 2 of the pertinent features. None were retained as a possible diagnosis in this case.

One remarkable feature we report here is the onychodysplasia of the index fingers. COIF, known also as Iso-Kikuchi disease (Iso, 1969; Kikuchi, Horikawa, \& Amano, 1974), is a rare disorder characterized by the following five criteria: congenital occurrence, unilateral or bilateral nail dystrophy of the index fingers, variability in nail appearance, bone abnormalities, and possible autosomal dominant inheritance (Baran \& Stroud, 1984). In the present subjects, there were no bone abnormalities and the inheritance seemed mostly autosomal recessive. Furthermore, in COIF, no short stature or ID have been described.

Franceschini, Licata, Guala, Di Cara, and Franceschini (2001) described a COIF patient with mild ID, dysmorphic facial features, and inguinal hernias. However, the ID was considered to be caused by his epilepsy, and his facial features were distinct from those reported here'. In addition, other important features seen in the individuals reported herein, such as DD, subglottic stenosis, short stature, and absence of speech were not found in the individual described by Franceschini et al.

Other syndromes with nail abnormalities have also been described. Congenital anonychia (OMIM 161050; 206800) lacks skeletal abnormalities of the distal phalanges such as in the individuals reported herein, but all nails are usually affected. The nail-patella syndrome (OMIM 161200), Poland syndrome (OMIM 173800), DOOR syndrome (OMIM 220500), and Tonoki syndrome (Tonoki, Kishino, \& Niikawa, 1990) were all ruled out because of the absence in the present cases of the major features seen in these syndromes. Furthermore, known genes involved in the latter syndromes were fully covered by our exome analysis and were found to be normal. Ectodermal dysplasia syndromes that can present with nail dysplasia were also ruled out because of the normal skin, hair, and teeth.

The presence of subglottic stenosis in all four of the subjects is another intriguing finding. Congenital subglottic stenosis, defined as a partial or complete narrowing of the endolarynx, is generally seen as a sporadic occurrence and is rarely found to run in families (Manickavasagam, Yapa, Bateman, \& Thevasagayam, 2014). Depending on the severity of obstruction, stenosis is classified into grades I to IV where grade IV indicates a complete obstruction and no detectable lumen (Cotton, 2000). In the present cases, individuals 2 and 4 were found to have a grade III, while the other two subjects were seen to have a grade II. The subjects were evaluated for syndromes with subglottic stenosis as a feature, including trisomy 21, Chromosome 22q11.2 deletion syndrome (OMIM 611867), Geleophysic Dysplasia 3 (OMIM 617809), psychomotor retardation, epilepsy and craniofacial dysmorphism (OMIM 614501), none of which fit the phenotype seen in this study. Additionally, analysis of the genes associated with these disorders did not uncover any mutations.
The facial features reported here consist of a round face, long palpebral fissures, thin lips and a short philtrum. Individually, these features are observed in several other syndromes. For instance, hyperphosphatasia (OMIM 239300), Kabuki syndrome (OMIM 147920), and KBG syndrome (OMIM 148050), all feature long palpebral fissures, however they lack other phenotypic characteristics exhibited by the four subjects. Collectively, the facial dysmorphic features observed here result in a distinct appearance, not seen in other syndromes.

Broad halluces, with or without hammer toes, are featured in several syndromes, the closest of which to the syndrome described here are Rubinstein-Taybi syndrome (OMIM 180849) and a syndrome described by Nampoothiri et al. (2011). The former has been ruled out by different facial features, as well as general thumbs and toes aspects in the individuals reported here. Moreover, Rubinstein-Taybi syndrome shows autosomal dominant transmission, which is unlikely in the family reported here. Nampoothiri et al. (2011), described two siblings who share certain features with the subjects described here such as ID, hearing impairment and broad halluces, but with different facial features and normal stature. Furthermore, the two siblings did not exhibit the nail onychodysplasia and subglottic stenosis described here, also absent in individuals with Rubinstein-Taybi syndromes.

Based on these findings, it is believed that the four individuals represent a previously unseen autosomal recessive syndrome. While WES failed to identify the causal variant(s), it is hoped that whole genome analysis will clarify the gene(s) involved. In conclusion, we report here a multiply consanguineous Syrian family where four young subjects and possibly a deceased aunt presented a unique cluster of anomalies. The marked level of consanguinity in this pedigree indicates an autosomal recessive inheritance of a syndrome not previously described. The defining phenotypic features of this syndrome will be better outlined once more families are diagnosed with this novel syndrome.

\section{ACKNOWLEDGMENTS}

We are thankful to the family for their cooperation and sharing of clinical information, despite being abroad.

\section{CONFLICT OF INTEREST}

The authors declare no potential conflict of interest.

\section{AUTHOR CONTRIBUTIONS}

André Mégarbané designed the study. André Mégarbané, Alicia Gambarini, and Valérie Delague, performed main experiments. Valérie Delague did the bioinformatical analysis. André Mégarbané, Sayeeda Hana, and Stephany El Hayek wrote the paper. André Mégarbané, Sayeeda Hana, Stephany El Hayek, Alicia Gambarini, Mahmoud Taleb Al-Ali, and Valérie Delague critically analyzed the results. All authors discussed and interpreted data, and edited the manuscript.

\section{DATA AVAILABILITY STATEMENT}

Data sharing is not applicable to this article as no new data were created or analyzed in this study. 


\section{ORCID}

André Mégarbané https://orcid.org/0000-0003-0714-2469

\section{REFERENCES}

Abou Jamra, R., Wohlfart, S., Zweier, M., Uebe, S., Priebe, L., Ekici, A., ... Reis, A. (2011). Homozygosity mapping in 64 Syrian consanguineous families with non-specific intellectual disability reveals 11 novel loci and high heterogeneity. European Journal of Human Genetics: EJHG, 19 (11), 1161-1166. https://doi.org/10.1038/ejhg.2011.98

Adzhubei, I. A., Schmidt, S., Peshkin, L., Ramensky, V. E., Gerasimova, A., Bork, P., ... Sunyaev, S. R. (2010). A method and server for predicting damaging missense mutations. Nature Methods, 7(4), 248-249. https://doi.org/10.1038/nmeth0410-248

Al-Gazali, L., \& Hamamy, H. (2014). Consanguinity and dysmorphology in Arabs. Human Heredity, 77(1-4), 93-107. https://doi.org/10.1159/ 000360421

Baran, R., \& Stroud, J. D. (1984). Congenital onychodysplasia of the index fingers. Iso and Kikuchi syndrome. Archives of Dermatology, 120(2), 243-244.

Choi, Y., Sims, G. E., Murphy, S., Miller, J. R., \& Chan, A. P. (2012). Predicting the functional effect of amino acid substitutions and indels. PLOS ONE, 7(10), e46688. https://doi.org/10.1371/journal.pone.0046688

Cotton, R. T. (2000). Management of subglottic stenosis. Otolaryngologic Clinics of North America, 33(1), 111-130. https://doi.org/10.1016/ s0030-6665(05)70210-3

Desvignes, J. P., Bartoli, M., Delague, V., Krahn, M., Miltgen, M., Béroud, C., \& Salgado, D. (2018). VarAFT: A variant annotation and filtration system for human next generation sequencing data. Nucleic Acids Research, 46(W1), W545-W553. https://doi.org/10.1093/nar/ gky471

Franceschini, P., Licata, D., Guala, A., Di Cara, G., \& Franceschini, D. (2001). Peculiar facial appearance and generalized brachydactyly in a patient with congenital onychodysplasia of the index fingers (IsoKikuchi syndrome). American Journal of Medical Genetics, 98(4), 330-335. https://doi.org/10.1002/1096-8628(20010201)98:4<330:: aid-ajmg1104>3.0.co;2-d

Iso, R. (1969). Seikeigeka. Orthopedic Surgery, 20(14), 1383-1384.

Kikuchi, I., Horikawa, S., \& Amano, F. (1974). Congenital onychodysplasia of the index fingers. Archives of Dermatology, 110(5), 743-746.

Kumar, P., Henikoff, S., \& Ng, P. C. (2009). Predicting the effects of coding non-synonymous variants on protein function using the SIFT algorithm. Nature Protocols, 4(7), 1073-1081. https://doi.org/10.1038/ nprot.2009.86

Li, H., \& Durbin, R. (2009). Fast and accurate short read alignment with burrows-wheeler transform. Bioinformatics (Oxford, England), 25(14), 1754-1760. https://doi.org/10.1093/bioinformatics/btp324

Manickavasagam, J., Yapa, S., Bateman, N. D., \& Thevasagayam, M. S. (2014). Congenital familial subglottic stenosis: A case series and review of literature. International Journal of Pediatric Otorhinolaryngology, 78(2), 359-362. https://doi.org/10.1016/j.ijporl.2013.10.049

McKenna, A., Hanna, M., Banks, E., Sivachenko, A., Cibulskis, K., Kernytsky, A., ... DePristo, M. A. (2010). The genome analysis toolkit: A MapReduce framework for analyzing next-generation DNA sequencing data. Genome Research, 20(9), 1297-1303. https://doi. org/10.1101/gr.107524.110

Nampoothiri, S., Kuthiroly, S., Fauth, C., Krabichler, B., Attie-Bitach, T., \& Hennekam, R. C. (2011). Macrostomia, thin upper vermilion border, long philtrum, broad halluces, and intellectual disability in two sibs. American Journal of Medical Genetics Part A, 155A(10), 2465-2468. https://doi.org/10.1002/ajmg.a.34205

Othman, H., \& Saadat, M. (2009). Prevalence of consanguineous marriages in Syria. Journal of Biosocial Science, 41(5), 685-692. https://doi.org/ 10.1017/S0021932009003411

Ozçelik, T., Kanaan, M., Avraham, K. B., Yannoukakos, D., Mégarbané, A., Tadmouri, G. O., ... Levy-Lahad, E. (2010). Collaborative genomics for human health and cooperation in the Mediterranean region. Nature Genetics, 42(8), 641-645. https://doi.org/10.1038/ng0810-641

Salgado, D., Desvignes, J. P., Rai, G., Blanchard, A., Miltgen, M., Pinard, A., ... Béroud, C. (2016). UMD-predictor: A high-throughput sequencing compliant system for pathogenicity prediction of any human cDNA substitution. Human Mutation, 37(5), 439-446. https://doi.org/10. 1002/humu.22965

Schwarz, J. M., Rödelsperger, C., Schuelke, M., \& Seelow, D. (2010). MutationTaster evaluates disease-causing potential of sequence alterations. Nature Methods, 7(8), 575-576. https://doi.org/10.1038/ nmeth0810-575

Scott, E. M., Halees, A., Itan, Y., Spencer, E. G., He, Y., Azab, M. A., ... Gleeson, J. G. (2016). Characterization of greater middle eastern genetic variation for enhanced disease gene discovery. Nature Genetics, 48(9), 1071-1076. https://doi.org/10.1038/ng.3592

Tadmouri, G. O., Nair, P., Obeid, T., Al Ali, M. T., Al Khaja, N., \& Hamamy, H. A. (2009). Consanguinity and reproductive health among Arabs. Reproductive Health, 6, 17. https://doi.org/10.1186/17424755-6-17

Tawamie, H., Martianov, I., Wohlfahrt, N., Buchert, R., Mengus, G., Uebe, S., ... Abou Jamra, R. (2017). Hypomorphic pathogenic variants in TAF13 are associated with autosomal-recessive intellectual disability and microcephaly. American Journal of Human Genetics, 100(3), 555-561. https://doi.org/10.1016/j.ajhg.2017.01.032

Teebi, A. (2010). Genetic disorders among Arab populations (2nd ed., p. 771). Manhattan, NY: Springer Ed. https://doi.org/10.1007/978-3642-05080-0

Teebi, A. S., \& Teebi, S. A. (2005). Genetic diversity among the Arabs. Community Genetics, 8(1), 21-26. https://doi.org/10.1159/000083333

Tonoki, H., Kishino, T., \& Niikawa, N. (1990). A new syndrome of dwarfism, brachydactyly, nail dysplasia, and mental retardation bs. American Journal of Medical Genetics, 36(1), 89-93. https:// rg/10.1002/ ajmg.1320360117

Wang, K., Li, M., \& Hakonarson, H. (2010). ANNOVAR: FI onal annotation of genetic variants from high-throughput sequen data. Nucleic Acids Research, 38(16), e164. https://doi.org/10.1093 /gkq603 